\title{
ABSTRACTS from the Denki-Kagaku Vol. 29
}

\section{Studies on Corrosion of Metals by Viscoplastic Substances. II. Influence on the Corrosion of Aluminum in Viscoplastic Substance by Addition of Halide, Especially Fluoride}

\author{
Minoru IzUyama and Yasumasa Hayakawa
}

Department of Chemistry, College of Liberal Arts, Saitama University, Urawa

Research has been made on the corrosion of aluminum in viscoplastic substance prepared from calcium carbonate by addition of fluoride and on the effect of inhibitor by the electrochemical methods such as potential-time curve measurement and cell current method, in which the current of the cell combined with platinum and aluminum specimen is measured.

1) The result obtained from the current-time curve measurement was similar to that of the corrosion potential measurment of the metals in viscoplastic substance.

2) The results obtained from the corrosion potential or cell current measurement were similar to that of the weight loss measuring method. Then the electrochemical methods such as the corrosion potential measurement are significant ways in corrosion test of viscoplastic substance.

3) The corrosion in case of the addition of $\mathrm{NaCl}, \mathrm{NaBr}$ or $\mathrm{NaI}$ had very small difference to that in case of no addition; while in case of $\mathrm{NaF}$ the corrosion grew larger than that in case of no addition.

4) The order of acceleration of various cations of fluorides on corrosion of aluminum in viscoplastic substance was as follows; $\mathrm{Na}^{+}>\mathrm{NH}_{4}{ }^{+}>\mathrm{Mg}^{2+}, \mathrm{Ca}^{2+}>$ blank $>\mathrm{Zn}^{2+}>\mathrm{Sn}^{2+}$.

5) The penetration was proportional to the concentration of sodium fluoride in this experiment (the amount of additives was below $2.35 \times 10^{-2} \mathrm{~g}$ eq. $\mathrm{NaF} / 100 \mathrm{~g}$ viscoplastic substance), while the addition of inhibitor such as sodium silicate was satisfactory for the inhibition of these corrosion of aluminum.

(Denki-Kagaku 29, 873 (1961))

\section{New Method of Measurement of Bromine Acceptance of Gelatin by Photodecomposition of Silver Bromide}

\author{
Sinichi Kikuchi*, Yuji Hamano**, Shoro Haginoya***, and Masako SaSaki* \\ * Institute of Industrial Science, University of Tokyo, Ryudocho, Minato-ku, Tokyo \\ ** Faculty of Engineering, University of Kanagawa, Kanagawa-ku, Yokohama \\ *** Oriental Photograph K.K., Shinjuku-ku, Tokyo
}

It was difficult to determine the reaction quantity of gelatin with bromine by potentiometric titration due to irreversibility and small rate of said reaction. The present report aims to improve the potentiometric method for measurement of the bromine asseptance of gelatin with a new and rather reproducible means.

This method comprises producing bromine photolysis of silver bromide grains of possibly homo- 
geneous size suspended in potassium bromide aqueous solution which contains a known quantity of gelatin and measuring the potential of platinum electrode immersed in said solution and combined with saturated calomel electrode. The photolysis is obtained by the irradiation of silver bromide grains to the mercury lamp. The producing rate of photolytic bromine is controlled by light intensity, concentration of silver bromide and grain size of silver bromide.

Employing said method, the capacities of bromine acceptance of 8 different kinds of photographic gelatines, 2 artificial photographic binders and 7 photographic active substances were measured. From results of experiments the authors would like to conclude that (1) PVA, CMC and reducing sugars have no capacities of bromine acceptance, (2) so-called inert gelatins generally accept less bromine than the sensitizing types, nevertheless even inert types have considerable capacities, (3) thiosulfate and cysteine are oxidized rapidly by bromine, (4) oxidation of nitrite by bromine is peculiar and (5) reaction rates of gelatins with bromine are small even in $0.01 \%$ concentrations.

(Denki-Kagaku 29, 480 (1961))

\title{
A Study on the Recovery of Vanadium in the Process of Producing Iron Sand Pig Iron. I. The Recovery of High Vanadium Slag Residually Produced in the Refining Process of Iron Sand Pig Iron
}

\author{
Toshio Taira, Takashi Kojima and Yoshinobu Otsuka \\ Technical Department, Nisso Steel Mfg. Co., Ltd., Chiyoda-ku, Tokyo
}

The authors engaged in manufacturing pig iron from iron sand which is mined at low cost and lies scattered abundantly almost over Japan, and in refining such pig iron in electric furnaces to produce pig iron of high quality, pure iron and low carbon pig iron for the use of special steel, and studied on the industrial recovering of the high vanadium slag as by-product in the refining processes. In consequence, the following results were obtained.

(1) On producing pure iron ingot from iron sand pig iron, vanadium content in the slag produced in the oxygen blowing refining process reached a peak after 10 minutes from beginning of such oxygen blowing, and then its content decreased.

(2) Less than $60 \mathrm{kgs}$. of slag making material per ton of iron sand pig iron, and about 35 minutes oxygen blowing were necessary for recovering high vanadium slag in the process of producing low carbon pig iron for the use of special steel from iron sand pig iron.

As a result of the statistical analysis of the practical operation which was made with the above conditions, the following formulae were obtained.

$$
\begin{aligned}
& (V) \%=0.2122 V_{q}-0.021 M+2.487 \\
& V_{r}=0.9039 V_{q}+0.8234 M+1.784 \\
& \text { where }
\end{aligned}
$$

$(V)=$ Percentage of vanadium content in high vanadium slag

$V_{q}=$ Quantity of vanadium content in iron sand pig iron $(\mathrm{kg})$

$M=$ Quantity of slag making material ( $\mathrm{kg} / \mathrm{pig}$ iron ton)

$V_{r}=$ Recovering rate of vanadium

(3) The authors stated that high vanadium slag could be industrially recovered as by-product in the oxygen blowing process for producing high quality pig iron, pure iron, and low carbon pig iron for the use of special steel. 


\title{
Research on the Air Depolarized Wet Cell with an Alkaline Zincate \\ Electrolyte. I. On the Composition of the Electrolyte and the Shape of the Zinc Cathode
}

\author{
Jun Watanabe, Tomizo Shiramoto and Rikio Iida
}

Dry Battery Department, Matsushita Electric Industrial Co., Ltd., Moriguchi, Osaka

Conventional air depolarized wet cells were required a large quantity of alkaline solution to keep zinc oxide in dissolved states.

In the present research it was attempted to obtain the requirements for improving the utilization rate of the electrolyte without changing the composition of electrolyte. The conclusions obtained were as follows:

1. By the use of an $\mathrm{KOH}$ electrolyte solution, the average voltage may be made higher and the capacity larger in comparison with the case of a $\mathrm{NaOH}$ solution.

2. The optimum concentration of $\mathrm{KOH}$ was about $35-40 \%$.

3. The addition of sodium polyacrylate had a remarkable effect to prevent zinc from being made passive. It was found that its concentration of about $1 \%$ is preferable.

4. By dissolving zinc oxide in an aqueous solution of $\mathrm{KOH}$, the terminal discharge voltage may satisfactorily be made smooth.

5. It became clear that by making the zinc cathode extremely porous, the zinc cathode is prevented effectively from being made passive.

It was found from those results that the amount of electrolyte may be reduced to about $1.7 \mathrm{cc}$ per 1 Ah in contrast with about $8 \mathrm{cc}$ per 1 Ah conventionally required.

(Denki-Kagaku 29, 645(1961))

\section{Electrochemical Studies of Sodium Chlorite. I. Specific Conductivity and Electrolytic Reaction of Sodium-Chlorite Aqueous Solution}

\author{
Genzo IsHi
}

The Japan Carlit Co., Gunma Works, Shibukawa, Gunma

Specific conductivity of sodium chlorite $\left(\mathrm{NaClO}_{2}\right)$ aqueous solution was measured at 25 and $60^{\circ} \mathrm{C}$, and its temperature coefficient was determined. The solution was considerably unstable at high temperatures, and it was not desirable to measure its conductivity at higher temperature above $60^{\circ} \mathrm{C}$.

In the next place, experiments were made on d. c. electrolytic reaction of sodium chlorite aqueous solution in both the cases of diaphragm and non-diaphragm processes, and its chemism was determined in each case. In particular, it was confirmed that electrolysis of diaphragm process was an excellent means to obtain chlorine dioxide $\left(\mathrm{ClO}_{2}\right)$ quantitatively from sodium chlorite, and its current efficiency, etc. were calculated. It was concluded that its electrolysis was possible at the current efficiency of nearly $100 \%$ under some proper conditions.

(Denki-Kagaku 29, 713 (1961)) 


\title{
Studies on the Mechanism of Magnesium Hydroxide Precipitation. IV. Structure and Properties of Dried New Magnesium Hydroxide
}

\author{
Takayasu SHIRASAKI
}

Research Laboratory of Resources Utilization, Tokyo Institute of Technology, Okayama, Meguro-ku, Tokyo

In the previous paper (PartIII), structure of "petal-like precipitates" obtained in the initial stage of formation of Brucite type crystal was studied, and these precipitates seemed to be hydrated magnesium hydroxide which had random layer structure constructed by two-dimensional magnesium hydroxide layers and $\mathrm{H}_{2} \mathrm{O}$ monolayers sandwiched each other. In this report, the structural characteristics of this compound which were derived from the presence of water layers were studied, and compared with the similar ones of hydrated clay-minerals. These studies elucidated that the "petal-like precipitates" had doubtlessly the above mentioned structure. The structural characteristics of this hydrated magnesium hydroxide are as follows.

(1) The lattice distance of cleavaged plane (001plane) becomes shorter as the dehydration proceeds. Namely, the sandwiched water layer which constructs a part of the layer structure decreases continuously on heating.

(2) Under the assumption that the sandwiched water can be removed completely without deformation of layer structure, (001) lattice distance of unhydrous matter becomes equal to that of Brucite. Therefore, it is concluded that the lattice distance of cleavaged plane is enlarged by the presence of sandwiched water layer.

(3) The (001) lattice distance is furthermore expanded by the intrusion of molecules of various glycoles into the structure. Degree of expansion is proportional to the size of intruding molecules. The lattice distance is shortened by the intrusion of methanol molecules. The intruded methanol molecules are hardly removed on heating.

The whereabouts of addition ion contained in group-b precipitate was estimated to be layer of sandwiched water. Furthermore, electron-microscopic observation indicated the presence of extremely thin membrane, width of which is nearly equal to that of single lattice layer.

(Denki-Kagaku 29, 708 (1961))

\section{Studies on the Mechanism of Magnesium Hydroxide Precipitation. V. Transformation of Hydrated Magnesium Hydroxide to Brucite-type Crystal and Effects of Addition Ions}

\author{
Takayasu SHIRASAKI
}

Research Laboratory of Resources Utilization, Tokyo Institute of Technology, Okayama, Meguro-ku, Tokyo

To make clear the mechanism of secondary stage reaction, the hydrated magnesium hydroxide precipitate was separated from the mother-liquor and their transformation (crystallization) to the Brucitetype crystals were studied on the various reaction conditions. Furthermore, the effects of addition ion contained in this separated precipitate on their crystal growth were investigated. The results obtained 
are as follows.

This transformation into Brucite-type crystals occurs slowly even on the complete drying state. This solid reaction occurs very slowly, but is extremely promoted by the presence of free water, exerting as a mineralyser.

This transformation, mainly sizes and forms of crystals are influenced by the chemical components of liquid medium in which the precipitate is suspended. For example, the higher concentration of magnesium ion in the medium gives the larger size of crystals. The crystals obtained are mostly irregular shaped platelets or the aggregation of these. The platelets are polycrystals consisted of many single crystals of which only c-axes are placed in parallel each other, but a-axes are irregularly arranged. The single crystals of hexagonal shaped platelets are obtained by suspending the precipitate in the sodium hydroxide solution.

The addition ion contained in the group- $\boldsymbol{b}$ precipitate of hydrated magnesium hydroxide remains in the Brucite-type crystals, even if this crystallization is brought out in the pure water, and the ion occluded in the dried crystals lengthens the lattice distance of (001) plane by $0.8 \%$. The addition ion prevents the crystal growth to (001) direction. These actions of the addition ion for this crystallization and the location of the ion contained in the hydrated magnesium hydroxide precipitate (mentioned in the previous paper) prove that the addition ion is apt to be adsorbed on the (001) planes of magnesium hydroxide precipitate in the course of their formation.

(Denki-Kagaku 29, 782 (1961)),

\title{
Studies on the Mechanism of Magnesium Hydroxide Precipitation. VI. On the Effect of Addition Ion on the Reaction Between Magnesium Sulphate Solution and Caustic Ammonia
}

\author{
Takayasu SHIRASAKI
}

Research Laboratory of Resources Utilization, Tokyo Institute of Technology, Okayama, Meguro-ku, Tokyo

The precipitates of Brucite-type crystals were usually obtained by the solution reaction between magnesium sulphate and caustic ammonia. These crystals are formed through the two step reactions as in the case of chloride and nitrate (see part $\mathbb{I}, \mathbb{I I I}, \mathrm{IV}$ ). When the appropriate addition ion was dissolved previously in the reaction solution, new basic magnesium sulphate $\left(5 \mathrm{Mg}(\mathrm{OH})_{2} \cdot \mathrm{MgSO}_{4} \cdot 21 \mathrm{H}_{2} \mathrm{O}\right)$ of needle crystals in place of Brucite ones was obtained. The citric, tartaric, polymetaphosphoric and malic anions mentioned in the previous report (part 1) were also found active in this case too.

The hydrated magnesium hydroxide precipitate which is deposited in the initial stage of this reaction can be also made stable by the addition of these four anions. When the appropriate amounts of the addition ion are added to the proper compositions of the reaction solutions, the reaction proceeds through the two steps as follows: the precipitate of stable hydrated magnesium hydroxide (which is hardly transformed into Brucite-type crystals) deposites at first, and then this precipitate reacts with magnesium sulphate in the mother-liquor, and thus gives the stable basic magnesium sulphate crystals. This course of reaction is observable by the electron-microscopic inspection.

The presence of the excessive addition ion in this reaction system prevented the crystallization of the basic magnesium sulphate. The hydrated magnesium hydroxide precipitate became very stable in this case, and thus the sufficient aging of the reaction mixtures gave the mixture of the basic magnesium 
sulphate crystals and Brucite-type one as the final products.

When the reaction was extremely slowly abvanced in the apparatus specially deviced for this purpose, no unstable intermediate products were observed, and basic magnesium sulphate crystals were deposited directly from the reaction solution irrespective of the presence of the addition ions.

(Denki-Kagaku 29, 846 (1961))

\title{
Fuel Cells. I. On the Oxygen Electrode for the High Temperature Fuel Cell
}

\author{
Takehiko Takahashi, Akiya Kozawa, Yoshisuke IwaI \\ Department of Applied Chemistry, Faculty of Engineering, Nagoya University, Chikusa-ku, Nagoya
}

A few preliminary experiments on the oxygen electrode for the high temperature fuel cell were carried out in order to examine polarization characteristics of the cathodic process: $\mathrm{O}_{2}+2 \mathrm{CO}_{2}+4 \mathrm{e} \rightarrow 2 \mathrm{CO}_{3}=$.

A rectangular metal plate $(1 \times 5 \mathrm{~cm})$ or a metal wire bundle were partly dipped into molten salt electrolyte: a mixture of $\mathrm{Na}_{2} \mathrm{CO}_{3}, \mathrm{~K}_{2} \mathrm{CO}_{3}$ and $\mathrm{Li}_{2} \mathrm{CO}_{3}$. Gases with various composition in $\mathrm{O}_{2} / \mathrm{CO}_{2}$ ratio were introduced onto these electrodes and the cathodic polarization was measued at $400-800^{\circ} \mathrm{C}$ by using a reference electrode, which is a silver wire electrode $\mathrm{O}_{2}+\mathrm{CO}_{2}(1: 1)$.

The results are summarized below.

1) Though the rectangular metal plate eletrode ( $\mathrm{Pt}$ or $\mathrm{Ag}$ ) should have very small reactive zone as a gas electrode, considerable electric current could be drawn: polarization of $300-400 \mathrm{mV}$ at $50 \mathrm{~mA}$ per electrode at $700-800^{\circ} \mathrm{C}$ with $\mathrm{CO}_{2}+\mathrm{O}_{2}(1: 1)$ was observed.

2) Static potential measurements indicated that both $\mathrm{O}_{2}$ and $\mathrm{CO}_{2}$ contributed to the cathode potential. When pure $\mathrm{O}_{2}$ or pure $\mathrm{CO}_{2}$ was passed over the electrode, the polarization was very high even at small current (5-10 mA per electrode). Much lower polarization was observed in a certain range of the gas composition $\left(30-80 \% \mathrm{O}_{2}, 70-20 \% \mathrm{Co}_{2}\right)$.

3) With a fixed gas composition of $\mathrm{CO}_{2}: \mathrm{O}_{2}=1: 1$, the polarization decreased with increase of the cell temperature ranging from 400 to $700^{\circ} \mathrm{C}$. Further increase of the temperature showed little change in the polarization.

4) In order to obtain approximate information on surface tension of the molten salt electrolyte, capillary raise of the electrolyte between the two metal plates was measured.

(Denki-Kagaku 29, 762 (1961)) 


\title{
Fuel Cell. II. On the Pre-oxidation of the Sintered Nickel Electrode
}

\author{
Takehiko TAKAhashi and Kaname Ito
}

Department of Applied Chemistry, Faculty of Engineering, Nagoya University, Chikusa-ku, Nagoya

The sintered nickel electrode covered with the $\mathrm{Ni}(\mathrm{Li})$ oxide layer is often used as the cathode of the fuel cell, for example, Bacon cell.

In order to make clear the formation phenomenon of the $\mathrm{Ni}(\mathrm{Li})$ oxide, the lithium contents and the electric resistances of the oxide layers which were produced on the nickel plates by the various conditions of the pre-oxidation were measured. And the cathodic polarization was studied at $200^{\circ} \mathrm{C}$ on the nickel plate electrode covered with the oxide layer.

The $\mathrm{Ni}(\mathrm{Li})$ oxide layer $\left(1-2 \mathrm{mg} / \mathrm{cm}^{2}\right)$ enough to protect the corrosion of the nickel cathode was produced by heating it at $700-800^{\circ} \mathrm{C}$ in the air after dipping in the $\mathrm{LiOH}$ solution. The content of $\mathrm{Li}$ in the oxide layer increased with the concentration of the $\mathrm{LiOH}$ solution. The nickel plate electrode treated with the $5-10 \% \mathrm{LiOH}$ solution had a small electric resistance $\left(1.5 \sim 8 \Omega / \mathrm{cm}^{2}\right)$ and could be used as the $\mathrm{O}_{2}$ gas electrode with a small polarization.

(Denki-Kagaku 29, 867 (1961))

\section{An Anomalous Property of Pd-H Electrode in Aqueous Solutions. II. Mechanisms of a Normal Hydrogen Electrode Reaction and an Anomalous Reaction}

\author{
Hajime SHIRATORI
}

Central Research Laboratory, Tokyo Shibaura Electric Co., Ltd., Kawasaki, Kanagawa

In the previous paper the author pointed out that two cathodic reactions on $\mathrm{Pd}-\mathrm{H}$ alloy in aqueous solution were found. One was the normal hydrogen electrode reaction and the other the anomalous reaction.

Mechanisms of both reactions remain at present unexplained. One must establish the perfectly stationary states, in order to investigate the kinetics of the anomalous hydrogen electrode reaction.

The author established the stationary states with the $\mathrm{Pd}-\mathrm{H}$ membrane electrode of which one side was polarized cathodically. In this case hydrogen atoms absorbed into the $\mathrm{Pd}-\mathrm{H}$ membrane electrode were compulsorily removed out from the another side.

Then the author was able to estimate experimentally that the transfer coefficient of the normal hydrogen electrode reaction is 0.5 , and that of the anomalous reaction is of the same value. From these facts it appears that the rate determining step of both reactions on the polarization side is Volmer reaction.

The rate determining step of the hydrogen evolution reaction which takes place on the diffusion side across the palladium membrane may be diffusion of proton in the $\mathrm{Pd}-\mathrm{H}$ alloy.

(Denki-Kagaku 29, 765 (1961)) 


\title{
Studies on the Escape of Chlorine in Chlorate Cell.
}

\section{On the Escape of Chlorine After the Disappearance of Free Hydrochloric Acid in Chlorate Cell}

\author{
Tatsuo Yокоу Ама
}

\author{
Faculty of Engineering, Toyama University, Takaoka, Toyama
}

When hydrochloric acid is added to the bath of a chlorate cell, free hydrochloric acid exists at the instant of addition, but it disappears after a very short time. After the disapperance of free hydrochloric acid, $\mathrm{Cl}_{2}$ and $\mathrm{HClO}$ will escape as follows :

$$
\begin{array}{cc}
\mathrm{HClO} \text { (as gas) } & \mathrm{Cl}_{2} \text { (as gas) } \\
\mathrm{Cl}^{-}+2 \mathrm{HClO} \text { (in liquid) } & \mathrm{H} \mathrm{ClO}^{-}+\mathrm{H}_{2} \mathrm{O}+\mathrm{Cl}_{2} \text { (in liquid) }
\end{array}
$$

We obtain from (1)

$$
P_{\mathrm{Cl}_{2}}=k C_{\mathrm{HClO}^{2}} C_{\mathrm{Cl}^{-}} / C_{\mathrm{ClO}^{-}}
$$

where $P_{\mathrm{Cl}_{2}}$ represents the vapor pressure of $\mathrm{Cl}_{2}$, and $C$ the concentration of each constituent.

We obtain from $(2)$

$$
\frac{1}{P_{\mathrm{Cl}_{2}}} \frac{d P_{\mathrm{Cl}_{2}}}{d t}=\frac{2}{C_{\mathrm{HClO}}} \frac{d C_{\mathrm{HClO}}}{d t}+\frac{1}{C_{\mathrm{Cl}^{-}}} \frac{d C_{\mathrm{Cl}^{-}}}{d t}-\frac{1}{C_{\mathrm{ClO}^{-}}} \frac{d C_{\mathrm{ClO}^{-}}}{d t}
$$

In (3), $\frac{1}{C_{\mathrm{HClO}}} \frac{d C_{\mathrm{HClO}}}{d t}$ is always negative but its absolute value is small, $\frac{1}{C_{\mathrm{Cl}^{-}}} \frac{d C_{\mathrm{Cl}^{-}}}{d t}$ is negative in general but in special cases it will be temporarily positive, and $\frac{1}{C_{\mathrm{ClO}^{-}}} \frac{d C_{\mathrm{ClO}^{-}}}{d t}$ will be temporarily negative with large absolute value. Therefore, $d P_{\mathrm{Cl}_{2}} / d t$ may be temporarily positive with large value.

When $d P_{\mathrm{Cl}_{2}} / d t$ is large enough, the escape of chlorine will increase with time for a while.

The above-mentioned state of affairs was explained theoretically and quantitatively. Experiments conducted the results of which coincided with the theory.

The following approximate formulas were derived in regard to the relation between the time and the concentration of each constituent.

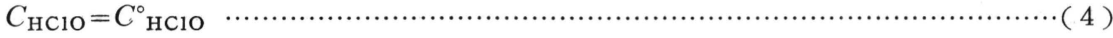

$$
\begin{aligned}
& C_{\mathrm{ClO}^{-}}=G / H+\left(C^{\circ} \mathrm{ClO}^{-}-G / H\right) \exp (-H t) \\
& C_{\mathrm{Cl}^{-}}=C^{\circ} \mathrm{Cl}^{-}+L t+M\{1-\exp (-H t)\} / H \\
& G=i / 2 \mathrm{FV}, \mathrm{H}=3 \mathrm{hi} / 200 \mathrm{FV}+\mathrm{KC}^{\circ} \mathrm{HClO}^{2} \\
& L=-i / 2 \mathrm{FV}+(\mathrm{G} / \mathrm{H})\left(7 \mathrm{ih} / 600 \mathrm{FV}+2 \mathrm{KC}^{\circ} \mathrm{HClO}^{2} / 3\right) \\
& M=\left(C^{\circ} \mathrm{ClO}^{-}-\mathrm{G} / \mathrm{H}\right)\left(7 \mathrm{ih} / 600 \mathrm{FV}+2 \mathrm{KC}^{\circ} \mathrm{HClO}^{2} / 3\right)
\end{aligned}
$$

where $t$ means the time elapsed since the addition of hydrochloric acid (the addition of the hydrochloric acid is supposed to be discontinuous), $C^{\circ}$ the concentration at $t=0, i$ the electric current, $F$ the Faraday constant, $V$ the effective volume of the bath, $K$ the apparent velocity constant of the reaction $2 \mathrm{HClO}+\mathrm{ClO}^{-}=2 \mathrm{HCl}+\mathrm{ClO}_{3}^{-}$, and $h$ current efficiency $(\%)$ of $\mathrm{ClO}^{-}$discharge $/ \mathrm{C}_{\mathrm{ClO}^{-}}$.

In the derivation of above-described formulas, some assumptions were made, the important ones of which were (1) $h$ is a constant, (2) the cathodic reduction is negligible, (3) the escape of chlorine is negligible, etc.

Formula (5) was verified by experiment. 


\title{
Studies on the Escape of Chlorine in Chlorate Cell. III. The Effect of Draught on the Escape of Chlorine
}

\author{
Tatsuo Yokoyama and Keiichi Nishibe
}

Faculty of Engineering, Toyama University, Takaoka, Toyama

The escape of chlorine from chlorate cell is considered to increase with the increase of draught from outside, but there was hitherto no report of such an experiment. Some experiments were conducted to make clear the extent of the increase of the escape of chlorine by the draught from outside.

Electrolytic cell was $1 l$ wide-mouthed bottle. Both the anode and the cathode were platinum plates $(25 \mathrm{~mm} \times 50 \mathrm{~mm})$ in some cases, but in the other cases the anode was magnetic iron oxide rod (diameter $30 \mathrm{~mm}$ ) and the cathode was iron wire spiral. Temperatures were chosen between about $25^{\circ} \mathrm{C}$ and $45^{\circ} \mathrm{C}$. The escape of chlorine really increased with the increase of draught, but the increasing rate of the former seemed to derease with the increase of the latter.

The increase of the escape of chlorine by the draught from outside must be due to the increase of evaporation or decrease of absorption of chlorine at the surface of the bath.

(Denki-Kagaku 29, 787 (1961))

\section{Studies on the Escape of Chlorine in Chlorate Cell. \\ IV. Influence of the Position of the Electrodes and the Methods of Addition of Hydrochloric Acid on the Escape of Chlorine}

\author{
Tatsuo Yokoyama and Keiichi Nishibe \\ Faculty of Engineering, Toyama University, Takaoka, Toyama
}

\section{Influence of the position of electrodes}

Influence of the position of electrodes on the escape of chlorine in experimental chlorate cell was investigated, the electrodes being platinum plates which were perpendicular and parallel to each other.

When both the anode and cathode were at the same depth, escape of chlorine became smaller as the position of electrodes became deeper. When the anode was shallow and the cathode was deep, the escape of chlorine was more than that in the case where the anode was deep and the cathode was shallow.

\section{Influence of method of the addition of hydrochloric acid}

When a large amount of concentrated hydrochloric acid was added at a time, there was a great difference between the case where the acid was dropped on the surface of the bath and the case where the acid was added to the bottom of the bath by some device. In the former case the escape of chlorine was far greater than in the latter case. However, when the acid used was dilute and small amounts of it were added at intervals, there was not much difference between the two cases.

Therefore, it is advantageous to add dilute acid little by little (i.e., almost continuously).

(Denki-Kagaku 29, 840 (1961)) 


\title{
AC-Impedance Measurement of Leclanché Cell Cathode
}

\author{
Shigeo Nagaura, Takao Murakawa and Kunio Ohashi \\ Department of Engineering, Osaka City University, Osaka
}

Using a similar apparatus to that of Cahoon, AC-impedance of a carbon cathode with/and without manganese dioxide on its surface was measured when discharge reaction took place. Values of impedance were shown as a combination of capacitance and resistance in series. With a carbon disk having no depolariser except oxygen on it, capacitance increased and resistance decreased. This tendency was quite contrary to that of the disk on which electrolytic manganese dioxide power was placed. On the other hand, when carbon powder was placed on the cathode, no appreciable change of impedance by discharge reaction was detected, because AC-current passed through only the carbon powder. Frequency characteristics of capacitance and resistance of each case was also measured in the range of $0.5-10 \mathrm{kc}$.

From these experiments, the authors have come to the following conclusions. (1) Impedance decrease of the carbon cathode without manganese dioxide is caused by the depletion of oxygen film covering the electrode. (2) Increase of the impedance of the manganese dioxide electrode is caused by chemical reaction of manganese dioxide from higher oxide to lower one. In this case, it seems that active surface of the carbon electrode is covered by the discharge products.

(Denki-Kagaku 29, 789 (1961))

\section{Chemistry of Manganese Dioxide Dry Cells. XIV. Discharge Characteristics of Dry Cells for a Wide Variety of Uses}

\author{
Taketsugu Hirai and Masataro Fukuda
}

Central Research Lab., Matsushita Electric Industrial Co., Ltd., Kitakawachi-gun, Osaka

When dry cells are discharged, temporary decreasing phenomenon of terminal voltage is observed in many cases. Magnitude, shape and duration of the above phenomenon, which have a serious effect on the evaluation of discharge capacity, change in a complicated way in response to both the make-up conditons of dry cells and the discharge modes. This is one of the reasons why little information has been given for the fundamentals of the discharge characteristics in spite of the wide variety of uses. Thus, a study was made to examine the change in the shape of the discharge curves in various discharge modes from the view-point of the internal resistance change. Six kinds of D size dry cells with different zinc chloride concentration of the electrolyte were used as samples. It was confirmed that when load resistance is made lighter, rest period of intermittent discharge is longer or zinc chloride concentration of initial electrolyte is higher, the above mentioned temporary decrease of terminal voltage is greater accordingly, and eventually terminal voltage tends to go down monotonously with time, showing no definite minimum value. This shift can be explained to be the increase in the diffusion rate of zinc ions, which are produced at zinc anode, into the thin outer layer of the bobbin. Lastly a few problems about the discharge characteristics are further discussed.

(Denki-Kagaku 29, 794 (1961)) 


\title{
Studies on Manufacturing WC by the Carburization of $\mathrm{CaWO}_{4}$. I. The Carburization of $\mathrm{WO}_{3}$ in Vacuum Heating
}

\author{
Yonejiro Horiguchi, Toshio Matoba and Yasuhiko Ishimaru \\ Nigata Factory, Mitsubishi Metal Mining Co., Ltd., Nigata
}

The carburization of $\mathrm{WO}_{3}$ by $\mathrm{C}$ was studied in vacuum heating. Specimens were prepared as follows: A. $\mathrm{WO}_{3}($ mean size $4.1 \mu)+\operatorname{Graphite}(3.2 \mu)$, B. $\mathrm{WO}_{3}(4.1 \mu)+$ carbon black $(<0.7 \mu)$ and C. finely precipitated $\mathrm{WO}_{3} \cdot \mathrm{H}_{2} \mathrm{O}+$ carbon black. These specimens were pressed into small tablets under pressure of $0.5 \mathrm{~kg} / \mathrm{mm}^{2}$. Specimen tablets put in a small graphite crucible were heated in a carbon tube heater in vacuum of $10^{-2} \mathrm{~mm} \mathrm{Hg}$ at a rate of temperature elevation of $10^{\circ} \mathrm{C} / \mathrm{min}$. Reaction products at various stages of heating temperature were analysed by means of X-ray and chemical methods, and their formation were shown by the pressure change due to gas evolution during operation. Results obtained may be sammarized as follows; (1) For the complete formation of WC it was necessary to heat over $1500^{\circ} \mathrm{C}$ with any of said specimens, but their reaction processes were different from each other. (2) For Cspecimens, the end of reaction was at about $800^{\circ} \mathrm{C}$, and $\alpha-\mathrm{W}_{2} \mathrm{C}$ was found at $900^{\circ} \mathrm{C}$, WC at $1100^{\circ} \mathrm{C}$. (3) For the same specimen, it was found $\alpha-\mathrm{W}_{2} \mathrm{C}$ at $1100^{\circ}$, but the end of $\mathrm{WC}$ formation was at $1200^{\circ} \mathrm{C}$. when heated under an atmospheric pressure, and it was different from the case of vacuum heating. (4) Carburization of $\mathrm{WO}_{3}$ by carbon may be advanced not only by the action of solid carbon but by that of $\mathrm{CO}$ gas. (5) Grain size of WC particles obeyd that of the $\mathrm{WO}_{3}$ and carbon particles as materials.

(Denki-Kagaku 29, 773 (1961))

\section{Studies on Manufacturing WC by the Carburization of $\mathrm{CaWO}_{4}$. II. The Carburization of $\mathrm{CaWO}_{4}$ by Carbon in Vacuum Heating}

\author{
Yonejiro Horiguchi, Toshio Matoba and Yasuhiko Ishimaru \\ Nigata Factory, Mitsubishi Metal Mining Co., Ltd., Nigata
}

It was studied the carburization of $\mathrm{CaWO}_{4}$ by carbon in vacuum heating. Added 7 moles of graphite or carbon black to 1 mole of $\mathrm{CaWO}_{4}$, and pressed it into small tablets under pressure of $0.5 \mathrm{~kg} /$ $\mathrm{mm}^{2}$.

The tablet specimen was heated in the furnace with carbon tube electrode in vacua of $10^{-2} \mathrm{~mm} \mathrm{Hg}$, and the reaction products were examined by means of X-ray and chemical analysis. The results obtained are as follows: (1) The reaction is different from that between $\mathrm{WO}_{3}$ and carbon, $i, e$, no $\mathrm{W}$ oxide is present even at the beginning of reaction, and $\mathrm{W}, \alpha-\mathrm{W}_{2} \mathrm{C}, \mathrm{WC}$ and $\mathrm{CaO}$ are formed by the decomposition of $\mathrm{CaWO}_{4}$. (2) $\mathrm{WC}$ is formed at a temperature over $1500^{\circ} \mathrm{C}$, and about $0.5 \%$ of $\mathrm{CaO}$ remains. (3) According to X-ray analysis it is shown that an unknown substance is found in a range of $1000^{\circ} \mathrm{C}$ to $1200^{\circ} \mathrm{C}$, and it diminishes at $1300^{\circ} \mathrm{C}$. This substance is to be examined by other experimental method.

(4) Pure WC would be obtained from carburization of $\mathrm{CaWO}_{4}$, because decomposed $\mathrm{Ca}$ or $\mathrm{CaC}_{2}$ can be removed during vacuum heating and a small amount of residual Ca may be separated from WC.

(Denki-Kagaku 29, 843 (1961)) 


\title{
Studies on Inhibitor for Metallic Aluminum in Basic Medium. III. Aminophenols in Basic Medium as Inhibitor for Metallic Aluminum
}

\author{
Katsuko Horiguchi, Yasuhiro Hagyuda and Yasumasa Hayakawa \\ Department of Chemistry, College of Liberal Arts, Saitama University, Urawa, Saitama
}

The mechanism of inhibitive action by organic inhibitors has been studied since 25 years ago. It is suggested that an organic substance having structure to form onium ion can form cation in acidic medium and show inhibitive effect due to the adsorption on cathode portion of metal surface. Hackerman concluded that inhibitive effect of organic substances is attributed to chemisorption between their lone pair electron and metal. Hayakawa et al. considered that there are many cases to show inhibitive action due to the formation of metal chelate compound other than physical and chemical sorptions from the results obtained by using $o$-hydroxyazo compounds and 8-hydroxyquinoline derivatives, as reported in the previous papers.

In this paper, the inhibitive actions of aminophenols are presented along the experiment in which the corrosion potential with lapse of time and the polarization characteristics are measured.

In $\mathrm{pH} 11.8$ medium, a chelate film of $o$-aminophenol was supposed to form on the aluminum surface, but the inhibitive action was not appreciable. $m$ - and $p$-aminophenols and toluidine which can not have structure to form chelate showed inhibitive effect due to sorption by polarity of amino-radical.

In $\mathrm{pH} 13.2$ medium, corrosion was promoted due to high alkalinity, and any chelate film was not observed even in the addition of $o$-aminophenol.

It was concluded that $o$-aminophenol showed inhibitive action, not due to forming chelate compound with aluminum even in alkaline medium.

(Denki-Kagaku 29, 855 (1961))

\section{A Study of Automatic Control for Cathodic Protection}

\author{
Saburo Fukui and Kenji Ueda
}

Laboratory of Mitsubishi Shipbuilding \& Engineering Co., Ltd., Akunoura, Nagasaki

In order to protect the metallic structure in sea water cathodically, it is necessary to polarize it equal to, or less noble than the protective potential.

The current density required for complete protection is extremely affected by temperature, flow rate and composition of sea water, etc. Thus, it is very difficult to protect the metallic structure completely.

In order to overcome these difficulties, an automatic controller for cathodic protection system, which can control the protective current automatically in accordance with the change of external conditions, was constructed.

The satisfactory performance of this controller has been confirmed by the application to the ships and to the bare iron plates submerged in water at the mouth of the River Urakami in the Nagasaki harbour.

(Denki-Kagaku 29, 858 (1961)) 


\title{
On the Azotation Reaction of Calcium Carbide Particles, Especially on the Fluidized Azotation. VI. Studies on Azotation Reaction of Calcium Carbide Particles
}

\author{
Yuji Minemura
}

Central Laboratory, Shin-Etsu Chemical Industry Co., Ltd., Ota-ku, Tokyo

The author studied the azotation phenomena of calcium carbide particles without sintering, by using a high-temperature microscope, a vibrating azotation apparatus, an azotating rotary kiln and a fluidized azotating furnace; and the reaction order, the control factor of the reaction, the reaction velocity and activation energy were obtained for each azotating process.

The results obtained were summarized as follows:

i. In the temperature range of under $1150^{\circ} \mathrm{C}$, the orders of the azotation reactions for all the above-mentioned processes, except for the vibrating azotation reactions, were the first order.

ii. The control factor of the azotating reaction of carbide particles without sintering was diffusion. process in the initial stage, and chemical reaction comprizing diffusion in the later stage.

iii. The reaction velocity of the azotation reaction of carbide particles without sintering was much smaller than that given in literatures. In the fluidized azotating reaction, the azotation velocity varied with the concentration of calcium cyanamide.

iv. The activation energy of calcium carbide particles azotated by the vibrating method, that of the intermediates of fluidized azotation as they were being completely azotated, and that of calcium carbide particles azotated by fluidization method with the fluidized bed consisted of highly concentrated calcium cyanamide were smaller than the activation energy of calcium carbide particles statically azotated.

(Denki-Kagaku 29, 862 (1961)) 